\title{
Design of Fuzzy Control Algorithm for Precious Irrigation System in Greenhouse
}

\author{
Ronghua Ji, Lijun Qi ${ }^{*}$, and Zicheng Huo \\ College of Information \& Electrical Engineering, \\ China Agricultural University, \\ Qinghua East Road. 17, 100083 Beijing, China
}

\begin{abstract}
The precious irrigation is of great significance for arid and semiarid area. According to the special environment of greenhouse, a fuzzy control algorithm was proposed to make an optimal irrigation strategy based on the actual measured soil humidity during the whole plant growth process. The fuzzy control system had two inputs (soil humidity error and its rate) and one output (water level difference). In this paper, the fuzzy control algorithm was introduced in detail which included the setting of input and output, the selection of membership function and the setting of fuzzy rules. The fuzzy control system was meaningful to the smart water-saving irrigation in greenhouse.
\end{abstract}

Keywords: soil humidity, fuzzy control algorithm, irrigation, greenhouse.

\section{Introduction}

Water is one of our precious natural resources. Water-saving irrigation is of great significance because there are many arid and semiarid areas in the word. The key in water-saving irrigation is striking to get balance for optimal plant grown with optimal usage of water. Many water-saving technologies were proposed by the researchers [1], such as drip irrigation [2] ,subsurface drip irrigation [3] and subsurface negative irrigation[4]. There were many research works which focused on the affection of different irrigation methods to crop. In order to find better irrigation scheduling with the compromise between high yield and great quality of greenhouse-grown tomato under limit water supply, two experiments of different irrigation treatments were conducted in the arid region of northwest China during spring to summer in 2008 (2008 season)and winter in 2008 to summer in 2009 [4]. Because the irrigation water use efficiency was very importance, the technical efficiency of unheated greenhouse farms in Tunisia was measured, and proposed a measure for irrigation water use efficiency (WUE) using an alternative form of the data envelopment analysis [5]. Application of the temporal and spatial deficit irrigation in field-grown crops had greater potential in saving water, maintaining economic yield and improving WUE [6].

Many conventional methods for controlling greenhouse irrigation were not effective since they were either based on on-off control methods or proportional

Corresponding author.

D. Li and Y. Chen (Eds.): CCTA 2011, Part III, IFIP AICT 370, pp. 278-283, 2012.

(C) IFIP International Federation for Information Processing 2012 
control methods which resulted in a loss of energy and productivity. A solution for an irrigation controller based on the fuzzy-logic methodology was presented [7]. The developed fuzzy logic controller could effectively estimate the amount of water uptake of plants in distinct depth using the reliable irrigation model, evaporation functions, environmentally conditions of the greenhouse, soil type, plant type and other factors affecting the irrigation of greenhouse. A fuzzy irrigation decisionmaking system was established by using virtual instrumentation platform [8]. The experiment results showed that the system had friendly interface and was easy to use; it could give comprehensive judgment and decision-making, and provide scientific basis for water saving irrigation. In our case, the irrigation system was very different.

The optimal water volume for plants was affected by many physical parameters such as air temperature, soil humidity, wind and stage of plant grown. Soil humidity was an important irrigation indicator to ensure the crop growing well. Because environment was controllable in greenhouse, some outside parameters were constant such as air temperature and wind. As for the irrigation system which was applied in greenhouse, the change of soil humidity was the most importance and direct parameter for irrigation strategy which included irrigation time and the irrigation volume. The fuzzy control algorithm was proposed for greenhouse precision irrigation system in this paper.

\section{Materials and Methods}

The soil water movement and distribution in soil was seriously affected by the irrigation strategy. In this paper, a precision irrigation system was used. The precision irrigation system consisted of five parts: a plant container, a built-in reservoir, a level control tank, a reservoir and a height adjuster. The scheme of precision irrigation system was shown in Fig. 1.

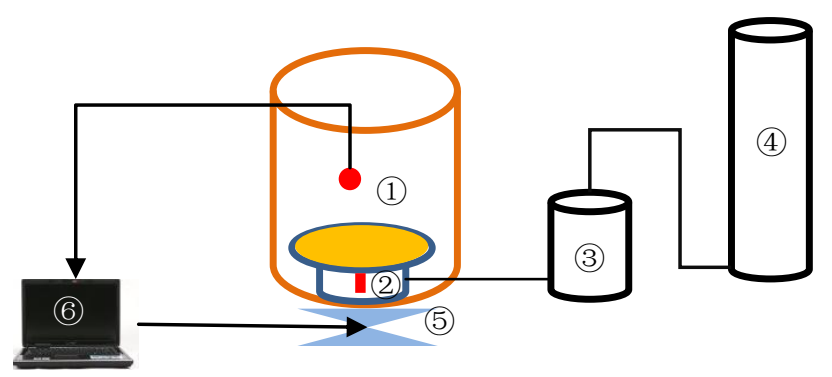

Fig. 1. The scheme of precision irrigation system

(1) the plant container; (2)the built-in reservoir; (3) the level control tank; (4) the reservoir; (5) the height adjuster; (6) the fuzzy controller in computer.

The soil humidity of plant container was affected by the water level difference between built-in reservoir and the level control tank. The water level difference was adjusted by the height adjuster which was controlled by the fuzzy controller in PC. Fuzzy controller had been widely applied as a powerful methodology for complicated 
nonlinear delay systems which were difficult to set up accurate mathematic models. The control strategy in controller was selected as fuzzy control because soil humidity was large delay, great inertial, time-varying and non-linearity.

The fuzzy controller was determined by the height of height adjuster based on the soil humidity error and its rate. The principle diagram of fuzzy control in this system was shown as in Fig.2.

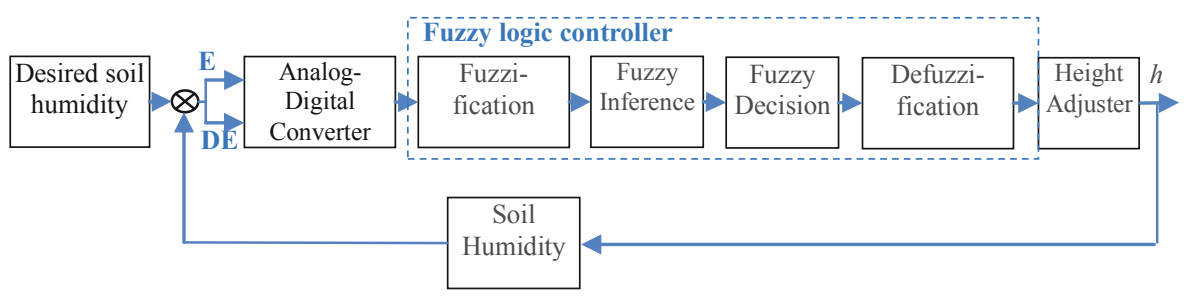

Fig. 2. The principle diagram of fuzzy controller

E was the soil humidity error which was defined as desired soil humidity minus actual soil humidity. DE was the rate of soil humidity error which was defined in equation (2).

$$
\begin{aligned}
\mathrm{E} & =H_{d}-H_{a} \\
\mathrm{DE} & =\frac{H_{d}-H_{a}}{H_{d}}
\end{aligned}
$$

Where $H_{d}$ was desired soil humidity, $H_{a}$ was actual soil humidity. The best range of soil humidity in every crop growing stage was ascertained according to the previously experimental data. The medium value of the best range of soil humidity was taken as the desired soil humidity.

The output of fuzzy control system was $h$ which was used adjusting the water level difference between built-in reservoir and the level control tank and changing soil humidity.

The soil humidity was always lower than desired value. The range of $\mathrm{E}$ was [-6\%, $0]$ and the range of DE [-1\%,0]. The input variables (E and DE) had 4 fuzzy states which was $\{$ IL, IM, IS, IZ\}. The output variable $h$ had 4 fuzzy states which was $\{\mathrm{OL}, \mathrm{OM}, \mathrm{OS}, \mathrm{OZ}\}$. The ranges of input/output variables were following:

$$
\begin{gathered}
\mathrm{E}=\{-6,-5,-4,-3,-2,-1,0\} \\
\mathrm{DE}=\{-6,-5,-4,-3,-2,-1,0\} \\
h=\{0,1,2,3\}
\end{gathered}
$$

Because the input variables of fuzzy controller ( $E$ and $D E$ ) were measured as accurate, they should be fuzzed firstly according to the equation (3).

$$
y=\frac{6\left(x-\frac{a+b}{2}\right)}{b-a}
$$

Where $x$ was the accurate input variable and $y$ was the fuzzed value. The accurate input variables changed from a to b. $y$ should be taken as integer. 
The membership function of variables was importance to the fuzzy controller. Every fuzzy variable's membership functions should be defined respectively. There were many kinds of membership functions to meet the requirement of various variables. The general rule to select membership function was following: the higher sensitivity membership for little error and the fine stability membership for larger error. According to the changing regularity of soil humidity error and the membership selection rule, the membership functions of variables (IL and IM) were taken as triangle function, the membership functions of variables (IS and IZ) were taken as Gaussian function and the membership functions of (DE and $h$ ) were triangle function. The membership function assignment table was shown in Table 1 to 3 .

Table 1. The soil humidity error's membership function assignment table

\begin{tabular}{llllllll}
\hline \multirow{2}{*}{$\begin{array}{c}\text { Fuzzy } \\
\text { variable }\end{array}$} & \multicolumn{7}{c}{ The soil humidity error (E) } \\
\cline { 2 - 8 } & -6 & -5 & -4 & -3 & -2 & -1 & 0 \\
\hline IL & 1.0 & 0.6 & 0.2 & 0 & 0 & 0 & 0 \\
IM & 0.2 & 0.6 & 1 & 0.6 & 0.2 & 0 & 0 \\
IS & 0 & 0 & 0 & 0.5 & 1 & 0.5 & 0 \\
IZ & 0 & 0 & 0 & 0 & 0 & 0.5 & 1 \\
\hline
\end{tabular}

Table 2. The soil humidity error rate of membership function assignment table

\begin{tabular}{llllllll}
\hline \multirow{2}{*}{$\begin{array}{c}\text { Fuzzy } \\
\text { variable }\end{array}$} & \multicolumn{7}{c}{ The error rate of soil humidity $(\mathrm{DE})$} \\
\cline { 2 - 8 } & -6 & -5 & -4 & -3 & -2 & -1 & 0 \\
\hline IL & 1.0 & 0.5 & 0 & 0 & 0 & 0 & 0 \\
IM & 0 & 0.5 & 1 & 0.5 & 0 & 0 & 0 \\
IS & 0 & 0 & 0 & 0.5 & 1 & 0.5 & 0 \\
IZ & 0 & 0 & 0 & 0 & 0 & 0.5 & 1 \\
\hline
\end{tabular}

Table 3. The output membership function assignment table

\begin{tabular}{lllll}
\hline \multirow{2}{*}{$\begin{array}{l}\text { Fuzzy } \\
\text { variable }\end{array}$} & \multicolumn{4}{c}{ The error rate of soil humidity $(h)$} \\
\cline { 2 - 5 } & 0 & 1 & 2 & 3 \\
\hline OL & 0 & 0 & 0.5 & 1 \\
OM & 0 & 0.5 & 1 & 0.5 \\
OS & 0.5 & 1 & 0.5 & 0 \\
OZ & 1 & 0.5 & 0 & 0 \\
\hline
\end{tabular}

According to the experimental data and irrigation experience, the fuzzy control rules were shown in Table 4. 
Table 4. Fuzzy control rules table

\begin{tabular}{llllll}
\hline \multirow{2}{*}{ Input } & & \multicolumn{4}{c}{$\mathrm{DE}$} \\
\cline { 3 - 6 } & & IL & IM & IS & IZ \\
\hline \multirow{4}{*}{ E } & IL & OL & OL & OM & OZ \\
& IM & OM & OM & OS & OZ \\
& IS & OS & OS & OZ & OZ \\
& IZ & OZ & OZ & OZ & OZ \\
\hline
\end{tabular}

There were 16 fuzzy control rules in this system.

That was

$$
\text { If } \mathrm{E}=\mathrm{A}_{\mathrm{i}} \text { and } \mathrm{DE}=\mathrm{B}_{\mathrm{j}} \text { Then } \mathrm{h}=\mathrm{C}_{\mathrm{ij}}(\mathrm{i}, \mathrm{j}=3,2,1,0)
$$

Where the value of $A_{i}$ was set according to Table 1 and the value of $B_{j}$ was set according to Table 2 .

$$
\mathrm{C}_{\mathrm{ij}}=\mathrm{A}_{\mathrm{i}} \times \mathrm{B}_{\mathrm{j}}
$$

In this paper, the fuzzy control algorithm was simulated by the fuzzy control toolbox of Matlab. The fuzzy reasoning system surface was shown in Fig 3.

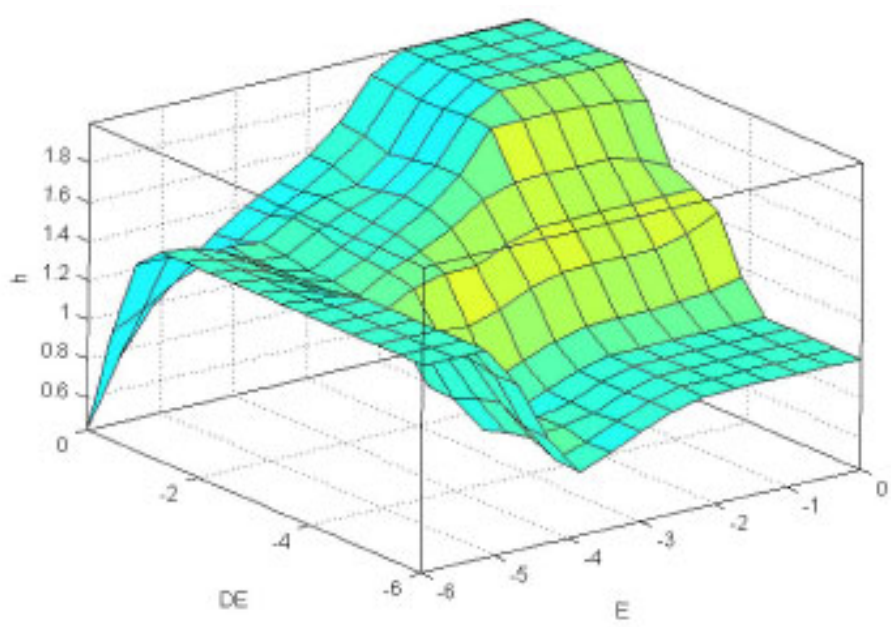

Fig. 3. The fuzzy reason system surface

\section{Conclusion}

In the greenhouse, the plant growth environment parameters were controllable, such as air temperature, wind and air humidity. The precious irrigation should be made the suitable irrigation strategy according to the requirements of plant growth. The irrigation strategy based on soil humidity and plant growth was an optimal irrigation to meet the actual need of plant growth. 
The fuzzy control algorithm was effective for the dynamic characteristics of soil humidity which was large delay, great inertial, time-varying and non-linearity. The fuzzy control system was meaningful with the water-saving irrigation in greenhouse.

Acknowledgments. The research is supported by the National Natural Science Funds (Project No. 31101609) and Chinese Universities Scientific Fund (Project No. 2011JS144).

\section{References}

1. Tal, A.: Seeking Sustainability: Israel's Evolving Water Management Strategy. Science 313, 1081-1084 (2006)

2. Caldwell, D.S., Spurgeon, W.E., Manges, H.L.: Frequency of irrigation for subsurface drip irrigation corn. Transactions of the ASAE 37, 1099-1103 (1994)

3. Ayars, J.E., Phene, C.J., Hutmacher, R.B., Davis, K.R., Schoneman, R.A., Vail, S.S., Mead, R.M.: Subsurface drip irrigation of row crops: a review of 15 years of research at the Water Management Research Laboratory. Agricultural Water Management 42, 1-27 (1999)

4. Wang, F., Kang, S., Du, T., Li, F., Qiu, R.: Determination of comprehensive quality index for tomato and its response to different irrigation treatments. Agricultural Water Management 98, 1228-1238 (2011)

5. Frija, A., Chebil, A., Speelman, S., Buysse, J., Van Huylenbroeck, G.: Water use and technical efficiencies in horticultural greenhouses in Tunisia. Agricultural Water Management 96, 1509-1516 (2009)

6. Du, T., Kang, S., Sun, J., Zhang, X., Zhang, J.: An improved water use efficiency of cereals under temporal and spatial deficit irrigation in north China. Agricultural Water Management 97, 66-74 (2010)

7. Javadi Kia, P., Tabatabaee Far, A., Omid, M., Alimardani, R., Naderloo, L.: Intelligent Control Based Fuzzy Logic for Automation of Greenhouse Irrigation Systemand Evaluation in Relation to Conventional Systems. World Applied Sciences Journal 6, 16-23 (2009)

8. Zhengjun, Q., Xiaoxing, T., Jiehui, S., Yidan, B.: Irrigation decision-making system based on the fuuzy-control theory and virtual instrument. Transactions of the CSAE 23, 165-169 (2007) 